ОСОБЕННОСТИ МОРФОФУНКЦИОНАЛЬНЫХ ПОКАЗАТЕЛЕЙ СЕРДЕЧНО-СОСУДИСТОЙ СИСТЕМЫ У МУЖЧИН МОЛОДОГО ВОЗРАСТА С ПРИЗНАКАМИ ДИСПЛАЗИИ СОЕДИНИТЕЛЬНОЙ ТКАНИ

\author{
С. В. Ефимов, Д. В. Черкашин, В. П. Андрианов, А. Е. Аланичев, \\ Г. Г. Кутелев, А. А. Либерман \\ ФГБВОУ ВО «Военно-медицинская академия имени С. М. Кирова» МО РФ, г. Санкт- \\ Петербург, Россия
}

\title{
PECULIARITIES OF MORPHOLOGOCAL AND FUNCTIONAL INDICES YOUNG MEN'S CARDIOVASCULAR SYSTEM WITH CONNECTIVE TISSUE DYSPLASIA SYMPTOMS
}

\author{
S. V. Efimov, D. V. Cherkashin, V. P. Andrianov, A. E. Alanichev, \\ G. G. Kutelev, A. A. Liberman
}

S. M. Kirov Military Medical Academy the Russian Defense Ministry, Saint Petersburg, Russia

Резюме. В настоящее время нет единой классификации и способов диагностики дисплазии соединительной ткани, однако известно, что все заболевания протекают с особенностями - в зависимости от степени выраженности нарушения соединительной ткани. Сама по себе дисплазия соединительной ткани, затрагивая все системы и органы в процессе эмбриогенеза, преимущественно проявляется в органах одной из систем. В настоящее время наиболее полно исследована сердечно-сосудистая система как обязательное звено адаптации организма к окружающей среде, она испытывает наиболее выраженные нагрузки при любой деятельности и патологии. Целью исследования было определить особенности морфофункциональных параметров жизнедеятельности организма здорового человека при минимальной степени выраженности признаков дисплазии соединительной ткани со стороны сердечно-сосудистой системы, а также определить 
количественные критерии оценки дисплазии соединительной ткани (6 табл., библ.: 17 ист.).

Ключевые слова: дисплазия соединительной ткани, объемная сфигмография, периферические артериальные сосуды, сердечно-сосудистая система.

\section{Статья поступила в редакцию 22.12.2016.}

Summary. Nowadays there is no uniform classification and methods of diagnosis of the dysplasia presence in the examined human connective tissue, however it is known that all diseases are depending especially on the severity of the connective tissue disorders. By itself, the connective tissue dysplasia, affecting all systems and organs in the process of embryogenesis, is manifested mainly in the bodies of one of the systems. So far, the cardiovascular system has been studied the most fully. It is considered as an obligatory element of adaptation to the environment, testing the most expressed load at any activity and pathology. The aim of the study was to determine peculiarities of morpho-functional parameters of a healthy person activity with a minimum of the severity of the symptoms of cardiovascular system connective tissue dysplasia, and also to determine quantitative criteria for the evaluation of DST (6 tables, bibliography: 17 refs).

Key words: cardiovascular system, dysplasia of connective tissue, peripheral arterial vessels, volume sphygmography.

\section{Article received 22.12.2016.}

Соединительная ткань составляет более $50 \%$ массы тела и является одной из четырех основных типов тканей организма человека [1-3]. В настоящее время определена структура и локализация генов, отвечающих за синтез различных элементов соединительной ткани. Мутации этих генов приводят к дефектам соединительной ткани, которые способствуют развитию 
патологических изменений в строении и функции различных органов и систем. Данные изменения в дальнейшем трактуются в рамках дисплазии соединительной ткани (ДСТ) [4-6]. Некоторые авторов считают ДСТ заболеванием при возникновении клинически значимых поражений органов и систем [7-9]. Другие авторы рассматривают ее только как сопутствующее состояние, выражающееся в морфологических изменениях, нарушении органогенеза и вегетативных расстройствах, которое меняет течение основного заболевания [10, 11]. ДСТ, затрагивая все системы и органы в процессе внутриутробного развития, преимущественно проявляется в органах одной из систем. Так, патология сердечно-сосудистой системы (CСС) у лиц с ДСТ имеет наиболее яркую и разнообразную клиническую картину. Постоянно протекающие дистрофические изменения в сосудистой стенке, метаболические изменения самого миокарда, обусловленные наличием ДСТ, способствуют понижению сопротивляемости ССС к остро возникающим изменениям гемодинамики. Соответственно заболевания системы кровообращения на фоне ДСТ ССС имеют особое течение. Например, лица с ДСТ на начальном этапе страдают артериальной гипотонией или нейроциркуляторной астенией, которая по мере прогрессирования нарушений соединительной ткани трансформируется в артериальную гипертензию [12, 13]. Повышение артериального давления (АД) при ДСТ имеет признаки симптоматической артериальной гипертензии, которую нельзя отнести к гипертонической болезни в связи с первичным поражением при ДСТ всех органов-мишеней; также ее трудно объяснить только патологией почек, центральной нервной системы или эндокринных желез [14]. Проявления сосудистого синдрома характеризуются поражением артерий эластического и мышечно-эластического типов, варикозным расширением вен верхних и нижних конечностей, варикоцеле, геморроем [15].

Общие изменения гемодинамики у лиц с признаками ДСТ ССС, обусловленные морфологическими изменениями сосудов и сердца, формируются уже в подростковом возрасте и с течением времени, прогредиентно усугубляясь, приводят к развитию недостаточности 
кровообращения [16]. В то же время раннее и своевременное выявление начальных симптомов ДСТ ССС у лиц молодого возраста позволяет не только провести коррекцию образа жизни таких людей, но и значительно уменьшить количество осложнений заболеваний ССС в зрелом возрасте.

\section{ЦЕЛЬ}

Определить морфофункциональные особенности системы кровообращения здорового человека при минимальной степени выраженности ДСТ ССС и рассмотреть возможность количественного подхода в ее диагностике, выявить наиболее информативные показатели из применяемых методик оценки ССС.

\section{МАТЕРИАЛЫ И МЕТОДЫ}

Исследовались 2 группы военнослужащих, проходивших медицинское освидетельствование в клинике военно-морской терапии с целью определения категории годности к военной службе, а также к воинской учетной специальности.

В первую группу вошли 76 человек военнослужащих по контракту, проходивших службу на Военно-морском флоте (ВМФ) (специалисты ВМФ) в возрасте от 20 до 44 лет. Вторая группа состояла из 28 курсантов Военноморского института (ВМИ) в возрасте от 19 до 24 лет.

Обе группы были обследованы с помощью регламентированных методов исследования, обязательных для медицинского освидетельствования (общеклинический и биохимический анализ крови, электрокардиография, велоэргометрия). Показатели находились в пределах нормативных значений, исключена общесоматическая патология, в частности такие заболевания ССС, как врожденные и приобретенные пороки сердца, нейроциркуляторная астения, 
гипертоническая болезнь, начальные формы ишемической болезни сердца. Дополнительно проводилась оценка центральной и периферической гемодинамики с помощью эхокардиографии (ЭхоКГ) (на эхокамере «Acuson Sequoia 512» (США)) и объемной сфигмографии (на аппарате «VaSera-1500N» фирмы «Fukuda Denshi» (Япония)). В обеих группах определялось наличие ДСТ ССС в соответствии с национальными российскими рекомендациями «Наследственные нарушения соединительной ткани» (І пересмотр, 2012 г.) по результатам клинической морфометрии и ЭхоКГ. Критерием наличия ДСТ ССС служило выявление хотя бы одного из перечисленных фенотипических признаков: расширения восходящего отдела аорты, пролапса митрального клапана, малых аномалий сердца (пролапсы трикуспидального и аортального клапанов, аневризма межпредсердной перегородки, открытое овальное окно, асимметрия трехстворчатого аортального клапана, диагональные, поперечные и множественные ложные хорды и множественные аномальные трабекулы левого желудочка), расширения ствола легочной артерии при отсутствии клапанного или периферического легочного стеноза до 40 лет, кальциноза митрального кольца в возрасте до 40 лет, расширения либо расслоения грудной или брюшной аорты в возрасте до 50 лет, варикозной болезни вен, развившейся в юношеском возрасте, варикоцеле, легкого образования гематом при незначительных травмах [17].

Статистическая обработка материала проводилась с помощью пакета прикладных программ STATISTICA 7.0 фирмы «StatSoft Inc.» (США). Для анализа однородности групп и вида распределения показателей применялись методы многомерной статистики. При сравнении групп использовались однофакторный дисперсионный анализ ANOVA и непараметрические критерии. Достоверными считались изменения при $\mathrm{p}<0,03$. 
В результате проведенных исследований все показатели в обеих группах не превышали возрастных нормативных показателей. При анализе результатов регламентированных методов исследования статистически значимых различий между группами не выявлено.

При сравнении показателей ЭхоКГ значимых различий между группами также не было выявлено (табл. 1).

Таблиия 1

\section{Сравнение (по Манну-Уитни)* показателей ЭхоКГ у обследуемых групп}

\begin{tabular}{|c|c|c|c|}
\hline Показатель & $\begin{array}{l}\text { Первая группа } \\
(\mathbf{n}=76)\end{array}$ & $\begin{array}{l}\text { Вторая группа } \\
(\mathbf{n}=\mathbf{2 8})\end{array}$ & $\mathbf{p}$ \\
\hline Диаметр корня аорты, см & $3,2(3,0 ; 3,5)$ & $3,1(3,0 ; 3,4)$ & 0,62 \\
\hline Диаметр восходящей аорты, см & $2,9(2,7 ; 3,0)$ & $2,7(2,6 ; 3,0)$ & 0,38 \\
\hline Диаметр дуги аорты, см & $2,6(2,4 ; 2,7)$ & $2,5(2,4 ; 2,6)$ & 0,06 \\
\hline Раскрытие створки аортального клапана, см & $1,97(1,90 ; 2,10)$ & $1,94(1,89 ; 2,00)$ & 0,10 \\
\hline Передне-задний размер левого предсердия, см & $3,90(3,50 ; 4,10)$ & $3,50(3,35 ; 3,75)$ & 0,06 \\
\hline Медиально-латеральный размер левого предсердия, см & $3,90(3,65 ; 4,05)$ & $3,45(3,30 ; 3,80)$ & 0,07 \\
\hline Продольный размер левого предсердия, см & $4,92(4,72 ; 5,18)$ & $4,95(4,70 ; 5,20)$ & 0,98 \\
\hline КДР ЛЖ, см & $5,22(4,90 ; 5,40)$ & $4,80(4,51 ; 5,10)$ & 0,05 \\
\hline КСР ЛЖ, см & $3,23(3,02 ; 3,35)$ & $3,10(2,90 ; 3,17)$ & 0,06 \\
\hline УО, мл & $82(75 ; 95)$ & $80(74 ; 94)$ & 0,35 \\
\hline$\Phi У, \%$ & $38(36 ; 42)$ & $37(34 ; 40)$ & 0,28 \\
\hline$\Phi B, \%$ & $68(65 ; 73)$ & $67(64 ; 72)$ & 0,49 \\
\hline Задняя стенка левого желудочка, см & $0,90(0,80 ; 0,94)$ & $0,90(0,80 ; 0,93)$ & 0,65 \\
\hline Межжелудочковая перегородка, см & $0,90(0,83 ; 0,93)$ & $0,90(0,82 ; 0,93)$ & 0,60 \\
\hline ИММ, Г/М ${ }^{2}$ & $101(91 ; 108)$ & $90(79 ; 100)$ & 0,07 \\
\hline OTC & $0,35(0,32 ; 0,37)$ & $0,34(0,32 ; 0,38)$ & 0,78 \\
\hline Диаметр ствола легочной артерии, см & $2,0(2,0 ; 2,2)$ & $2,0(1,9 ; 2,1)$ & 0,90 \\
\hline Среднее давление в легочной артерии, мм рт. ст. & $12,0(11,0 ; 18)$ & $11,0(10,0 ; 16,0)$ & 0,09 \\
\hline Медиально-латеральный размер правого предсердия, см & $3,5(3,3 ; 3,8)$ & $3,4(3,2 ; 3,8)$ & 0,46 \\
\hline Продольный размер правого предсердия, см & $4,6(4,4 ; 4,8)$ & $4,5(4,3 ; 4,8)$ & 0,75 \\
\hline $\begin{array}{l}\text { Конечный диастолический размер правого желудочка, } \\
\text { см }\end{array}$ & $2,6(2,4 ; 2,7)$ & $2,5(2,4 ; 2,7)$ & 0,06 \\
\hline Передняя стенка правого желудочка, см & $0,3(0,3 ; 0,4)$ & $0,3(0,3 ; 0,4)$ & 0,63 \\
\hline Скорость аортального потока, м/с & $1,32(1,30 ; 1,39)$ & $1,34(1,29 ; 1,40)$ & 0,12 \\
\hline Митральный поток (E/A), м/с & $1,4(1,3 ; 1,6)$ & $1,5(1,4 ; 1,7)$ & 0,30 \\
\hline Время замедления раннего & $174(170 ; 178)$ & $173(171 ; 177)$ & 0,31 \\
\hline
\end{tabular}




\begin{tabular}{|l|l|l|l|}
\hline трансмитрального потока, мс & & \\
\hline Пульмональный поток (АТ/ЕТ), с & $0,49(0,48 ; 0,50)$ & $0,50(0,48 ; 0,50)$ & 0,21 \\
\hline Скорость трикуспидального потока, м/с расслабления левого & $99(90 ; 104)$ & $2,09(1,93 ; 2,12)$ & 0,83 \\
\hline $\begin{array}{l}\text { Время изоволюмического } \\
\text { желудочка, мс }\end{array}$ & $98(93 ; 105)$ & 0,48 \\
\hline Время сокращения задней стенки левого желудочка, мс & $109(104 ; 116)$ & $110(103 ; 114)$ & 0,89 \\
\hline
\end{tabular}

Примечание. * - распределение, значительно отличающееся от нормального, описывается с помощью медианы и межквартильного размаха;(Верст.! Без выделения цветом!) КДР ЛЖ — конечный диастолический размер левого желудочка; КСР ЛЖ — конечный систолический размер левого желудочка; УО - ударный объем; ФУ — фракция укорочения; ФВ - фракция выброса; ИММ - индекс массы миокарда; ОТС — индекс относительной толщины стенок.

Однако отмечена тенденция в увеличении передне-заднего и медиально-латерального размеров левого предсердия, конечного систолического и диастолического размеров левого желудочка, ИММ у специалистов ВМФ по сравнению с курсантами ВМИ. Обследованные группы не различались по антропометрическим показателям, были однородны по воздействию профессиональных факторов. Поэтому выявленные изменения эхокардиографических показателей могут быть объяснены возрастными различиями между обследуемыми группами.

При оценке сосудистого компонента системы кровообращения методом объемной сфигмографии у первой группы по сравнению со второй установлено значимое повышение R-CAVI, L-CAVI, R-AI, RA-UT, LA-UT, RB\% MAP, LB-\%MAP, показателей биологического возраста сосудов, снижение Rtba, L-tba. В табл. 2 указаны только статистически значимые различия.(Верст.! Просьба дать табл. 2 выше этого абзаца, так как пояснения по поводу выделенных зеленым понятий даны в примечании к таблице!

Таблица 2

\section{Сравнение (по Манну-Уитни)* показателей объемной сфигмографии} обследуемых групा

\begin{tabular}{|ll|l|l|l|}
\hline Показатель & & $\begin{array}{l}\text { Первая группа } \\
(\mathbf{n = 7 6 )}\end{array}$ & $\begin{array}{l}\text { Вторая группа } \\
(\mathbf{n = 2 8})\end{array}$ & p \\
\hline R-CAVI & & $6,2(5,8 ; 6,6)$ & $5,5(5,1 ; 6,1)$ & 0,005 \\
\hline Нижняя граница биологического озаста & $23(20 ; 32)$ & $18(18 ; 20)$ & $<0,001$ \\
\hline
\end{tabular}




\begin{tabular}{|c|c|c|c|}
\hline сосудов справа, лет & & & \\
\hline $\begin{array}{lrr}\text { Верхняя граница } & \text { биологического } & \text { возраста } \\
\text { сосудов справа, лет } & & \end{array}$ & $28(24 ; 35)$ & $20(20 ; 24)$ & $<0,001$ \\
\hline L-CAVI & $6,1(5,8 ; 6,8)$ & $5,7(5,1 ; 6,2)$ & 0,005 \\
\hline $\begin{array}{l}\text { Нижняя граница } \text { биологического } \\
\text { сосудов слева, лет }\end{array}$ & $23(20 ; 33)$ & $18(18 ; 18)$ & $<0,001$ \\
\hline $\begin{array}{l}\text { Верхняя граница } \text { биологического } \\
\text { сосудов слева, лет }\end{array}$ & $27(24 ; 36)$ & $20(20 ; 20)$ & $<0,0005$ \\
\hline R-tba & $111(104 ; 118)$ & $116(110 ; 124)$ & 0,03 \\
\hline L-tba & $112(104 ; 117)$ & $118(109 ; 124)$ & 0,02 \\
\hline $\mathrm{R}-\mathrm{AI}$ & $0,77(0,71 ; 0,85)$ & $0,66(0,60 ; 0,75)$ & 0,006 \\
\hline RA-UT, mc & $134(127 ; 145)$ & $116(110 ; 127)$ & $<0,0002$ \\
\hline LA-UT, mc & $136(127 ; 143)$ & $118(111 ; 126)$ & $<0,0003$ \\
\hline RB-\%MAP & $46(44 ; 49)$ & $41(39 ; 44)$ & 0,001 \\
\hline LB-\%MAP & $47(45 ; 50)$ & $43(41 ; 46)$ & 0,008 \\
\hline
\end{tabular}

Примечание. * - распределение, значительно отличающееся от нормального, описывается с помощью медианы и межквартильного размаха; (Верст! Дать без выделения цветом!)R-CAVI — сердечнолодыжечный сосудистый индекс справа; L-CAVI — сердечно-лодыжечный сосудистый индекс слева; R-tba время между началом подъема пульсовой волны правого плеча и началом подъема пульсовой волны правой голени; L-tba - время между началом подъема пульсовой волны левого плеча и началом подъема пульсовой волны левой голени; R-AI — индекс аугментации; RA-UT — время подъема волны на правой голени; LA-UT — время подъема волны на левой голени; RB-\%MAP — среднее АД на правом плече, \%; LB-\%MAP - среднее АД на левом плече, \%.

Данные изменения свидетельствуют о повышении жесткости артериальных сосудов, снижении растяжимости сосудистой стенки в первой группе по сравнению со второй. Выявленные различия могут быть объяснены не только возрастными различиями между обследуемыми группами, но и особенностями артериальной сосудистой стенки, связанной с ДСТ.

В результате морфометрии и ЭхоКГ обследуемые группы были разделены на подгруппы в зависимости от наличия или отсутствия признаков ДСТ ССС (табл. 3).

Таблица 3

\section{Наличие ДСТ ССС в обследуемых группах}

\begin{tabular}{|l|l|l|}
\hline Количество признаков & $\begin{array}{l}\text { Первая группа } \\
(\mathbf{n = 7 6})\end{array}$ & $\begin{array}{l}\text { Вторая группа } \\
(\mathbf{n = 2 8})\end{array}$ \\
\hline Нет признаков ДСТ ССС & 48 & 19 \\
\hline Есть признаки ДСТ ССС & 28 & 9 \\
\hline
\end{tabular}


Из табл. 3 следует, что встречаемость ДСТ ССС в обеих группах была сопоставима, в то же время в каждой группе отмечалось преобладание обследуемых без признаков дисплазии. Эти особенности в сформированных группах связаны с отбором, в результате которого у военнослужащих с ДСТ ССС выявляются заболевания системы кровообращения, препятствующие дальнейшему обучению или службе на ВМФ.

На основании количественных данных ЭхоКГ и объемной сфигмографии предпринималась попытка определить факт наличия ДСТ ССС в группе специалистов ВМФ. Для этого первая группа была разделена на 2 подгруппы в зависимости от наличия ДСТ ССС: 1-я подгруппа - с ДСТ ССС, 2-я подгруппа - без ДСТ ССС. По результатам ЭхоКГ и объемной сфигмографии эти группы дифференцировались посредством дискриминантного анализа. Пошаговый дискриминантный анализ позволил разделить подгруппы с точностью 77,7\%, причем значимыми оказались 8 показателей с $\mathrm{p}=0,0009$. Отсутствие ДСТ ССС диагностировано с точностью до $87,5 \%$, наличие - с точностью до $67,9 \%$ (табл. 4).

Таблица 4

Распределение обследуемых по результатам дискриминантного анализа

\begin{tabular}{|l|l|l|l|l|}
\hline \multirow{2}{*}{ Фактически } & \multicolumn{2}{|l|}{ Прогноз } & \multirow{2}{*}{ Всего } & $\begin{array}{l}\text { Вероятность } \\
\text { распознавания, \% }\end{array}$ \\
\cline { 1 - 4 } & без ДСТ ССС & с ДСТ ССС & & правильного \\
\hline Без ДСТ ССС & 42 & 6 & 48 & 87,5 \\
\hline С ДСТ ССС & 9 & 19 & 28 & 67,9 \\
\hline Всего & 51 & 25 & 76 & 77,7 \\
\hline
\end{tabular}

Результаты дискриминантного анализа приведены в табл. 5.

Таблий 5

Группа показателей ЭхоКГ и объемной сфигмографии, связанных с ДСТ CCC

\begin{tabular}{|l|l|l|l|}
\hline Показатель & $\mathbf{B}$ & $\mathbf{p}$ & $\mathbf{r}$ \\
\hline $\mathrm{aaR}$, лет & $-0,57$ & 0,17 & $-0,07$ \\
\hline abR, лет & 0,603 & 0,15 & $-0,06$ \\
\hline DBPrb, мм рт. ст. & 0,205 & 0,004 & 0,00 \\
\hline
\end{tabular}




\begin{tabular}{|l|l|l|l|}
\hline DBPlb, мм рт. ст. & $-0,113$ & 0,04 & $-0,10$ \\
\hline SBPla, мм рт. ст. & $-0,059$ & 0,03 & $-0,15$ \\
\hline Aarc, см & $-7,24$ & $<0,0001$ & $-0,60$ \\
\hline LVDD, см & $-1,46$ & 0,08 & $-0,38$ \\
\hline RA2, см & 1,258 & 0,22 & $-0,07$ \\
\hline Константа & 18,25 & & \\
\hline
\end{tabular}

Примечание. В - коэффициент дискриминантной функции; aaR - нижняя граница биологического возраста сосудов справа; abR - верхняя граница биологического возраста сосудов справа; DBPrb - ДАД на правом плече; DBPlb - ДАД на левом плече; SBPla - CAД на левой голени; Аагс — диаметр дуги аорты; LVDD - КДР ЛЖ; RA2 - продольный размер правого предсердия

Индивидуально значимыми являлись диастолическое артериальное давление (ДАД)(Верст.! Просьба дать табл. 5 после формулы, так как впервые в тексте понятие и пояснение к аббревиатуре даны в этом абзаце!), правого плеча и диаметр дуги аорты. С использованием дискриминантной функции (ДФ) составлено решающее правило, позволяющее выделять лиц с признаками ДСТ CCC:

$$
\text { ДФ }=18,25-0,57 \times \mathrm{aaR}+0,603 \times \mathrm{abR}+0,205 \times \mathrm{DBPrb}-0,113 \times \mathrm{DBPlb}
$$

$-0,059 \times \mathrm{SBPla}-7,24 \times \mathrm{Aarc}-1,46 \times \mathrm{LVDD}+1,258 \times \mathrm{RA} 2 ;$ при ДФ $<0$ признаков ДСТ ССС нет, при ДФ > 0 признаки ДСТ ССС есть.

Для подтверждения решающего правила в качестве независимой выборки была использована вторая группа, состоящая из 28 курсантов ВМИ. Применение решающего правила из 8 показателей позволило выделить лиц, не имеющих признаков ДСТ на 87,9\%, и лиц, имеющих признаки ДСТ на 69,8\%. Таким образом, распознавание в случайной выборке дало значимый эффект правильного распознавания.

Процент распознавания, полученный с помощью дискриминантного анализа в обследуемых группах, позволяет рекомендовать комплекс методов оценки центральной и периферической гемодинамики для выявления признаков ДСТ ССС в процессе профессионального отбора специалистов ВМФ.

Однако правильность распознавания лиц с ДСТ ССС не превышала 70\%. Столь невысокий процент распознавания, возможно, связан с большим 
влиянием на тонус артериальной стенки возрастных особенностей. Для разграничения роли дисплазии и возрастного фактора нами был проведен следующий этап исследования, который включал сначала сравнение подгрупп с ДСТ ССС и без ДСТ ССС внутри группы, затем попарно сравнение подгрупп с ДСТ ССС и без ДСТ ССС обеих групп.

При сравнении подгрупп с ДСТ и без ДСТ внутри первой группы не выявлено статистически значимых различий для всех показателей. Внутри второй группы сравнение подгрупп с ДСТ и без ДСТ показало наличие слабых статистически значимых различий на уровне тенденций в показателях лодыжечно-плечевого индекса, систолического АД на обеих нижних конечностях. Следовательно, чем больше возраст, тем больше нивелируется влияние ДСТ на артериальную сосудистую стенку.

Данные попарного сравнения подгрупп с ДСТ ССС и без ДСТ ССС обеих групп приведены в табл. 6 и 7.

Таблицุа 6

\section{Сравнение* подгрупп с ДСТ ССС обеих групп по показателям объемной} сфигмографии(Верст.! Выравнивание всюду по 1-й строке!)

\begin{tabular}{|c|c|c|c|}
\hline \multirow[b]{2}{*}{ Показатель } & Первая группа & Вторая группа & \multirow[b]{2}{*}{$\mathbf{p}$} \\
\hline & $\begin{array}{l}\text { подгруппа с ДСТ } \\
(\mathbf{n}=\mathbf{2 8})\end{array}$ & $\begin{array}{l}\text { подгруппа с ДСТ } \\
(\mathbf{n}=9)\end{array}$ & \\
\hline R-CAVI & $6,3 \pm 0,6$ & $5,7 \pm 1,0$ & $0,02 * *$ \\
\hline $\begin{array}{l}\text { Нижняя граница биологического возраста } \\
\text { сосудов справа, лет }\end{array}$ & $30(25 ; 30)$ & $18(18 ; 20)$ & $0,0001 * *$ \\
\hline $\begin{array}{l}\text { Верхняя граница биологического возраста } \\
\text { сосудов справа, лет }\end{array}$ & $29(24 ; 34)$ & $20(20 ; 24)$ & $0,0002 * *$ \\
\hline L-CAVI & $6,3 \pm 0,6$ & $5,6 \pm 0,8$ & $0,01 * *$ \\
\hline $\begin{array}{l}\text { Нижняя граница биологического возраста } \\
\text { сосудов слева, лет }\end{array}$ & $25(20 ; 30)$ & $18(18 ; 18)$ & $0,0003 * *$ \\
\hline $\begin{array}{l}\text { Верхняя граница биологического возраста } \\
\text { сосудов слева, лет }\end{array}$ & $29(24 ; 34)$ & $20(20 ; 20)$ & $0,0003 * *$ \\
\hline R-tba & $111 \pm 10$ & $118 \pm 15$ & 0,14 \\
\hline $\mathrm{R}-\mathrm{AI}$ & $0,81 \pm 0,14$ & $0,69 \pm 0,12$ & 0,03 \\
\hline
\end{tabular}




\begin{tabular}{|l|l|l|l|}
\hline RA-UT & $138(129 ; 147)$ & $115(113 ; 129)$ & $0,0002^{* *}$ \\
\hline LA-UT & $138(124 ; 145)$ & $119(114 ; 133)$ & $0,003 * *$ \\
\hline RB-\%MAP & $47 \pm 5$ & $42 \pm 6$ & $0,01 * *$ \\
\hline LB-\%MAP & $47 \pm 4$ & $43 \pm 7$ & 0,04 \\
\hline
\end{tabular}

Примечание. * - распределение, близкое к нормальному, описывается с помощью среднего, значительно отличающегося от нормального медианой и межквартильным размахом; (Верст.! Убрать выделение цветом!)** — статистически значимые различия.

В подгруппах с ДСТ ССС первой и второй групп отмечалось статистически значимое увеличение показателей жесткости, биологического возраста, снижение эластичности артериальной сосудистой стенки у специалистов ВМФ.

Таблица 6

\section{Сравнение* подгрупп без ДСТ ССС обеих групп по показателям объемной сфигмографии}

\begin{tabular}{|c|c|c|c|}
\hline \multirow[b]{2}{*}{ Показатель } & Первая группа & Вторая группа & \multirow[b]{2}{*}{$\mathbf{p}$} \\
\hline & $\begin{array}{l}\text { подгруппа без ДСТ } \\
(\mathrm{n}=48)\end{array}$ & $\begin{array}{l}\text { подгруппа без ДСТ } \\
(\mathbf{n}=19)\end{array}$ & \\
\hline R-CAVI & $6,1 \pm 0,8$ & $5,7 \pm 0,7$ & 0,07 \\
\hline $\begin{array}{l}\text { Нижняя граница } \quad \text { биологического } \\
\text { возраста сосудов справа, лет }\end{array}$ & $25(20 ; 30)$ & $20(18 ; 21)$ & $<0,001 * *$ \\
\hline $\begin{array}{l}\text { Верхняя граница биологического } \\
\text { возраста сосудов справа, лет }\end{array}$ & $29(24 ; 34)$ & $20(20 ; 24)$ & $<0,0001 * *$ \\
\hline L-CAVI & $6,1 \pm 0,7$ & $5,8 \pm 0,8$ & 0,17 \\
\hline $\begin{array}{l}\text { Нижняя граница биологического } \\
\text { возраста сосудов слева, лет }\end{array}$ & $25(20 ; 30)$ & $19(18 ; 20)$ & $<0,001 * *$ \\
\hline $\begin{array}{l}\text { Верхняя граница биологического } \\
\text { возраста сосудов слева, лет }\end{array}$ & $29(24 ; 34)$ & $20(20 ; 22)$ & $<0,0001 * *$ \\
\hline R-tba & $111 \pm 10$ & $118 \pm 10$ & $0,01 * *$ \\
\hline R-AI & $0,77 \pm 0,11$ & $0,69 \pm 0,12$ & $0,01 * *$ \\
\hline RA-UT & $132(126 ; 144)$ & $118(108 ; 126)$ & $<0,0001 * *$ \\
\hline LA-UT & $131(125 ; 142)$ & $116(110 ; 126)$ & $<0,0001 * *$ \\
\hline RB-\%MAP & $45 \pm 4$ & $42 \pm 4$ & $0,01 * *$ \\
\hline LB-\%MAP & $47 \pm 4$ & $44 \pm 4$ & $0,02 * *$ \\
\hline
\end{tabular}


Примечание. * - распределение, близкое к нормальному, описывается с помощью среднего, значительно отличающегося от нормального медианой и межквартильным размахом; (Верст.! Убрать выделение цветом!)** — статистически значимые различия.

В подгруппах без ДСТ ССС первой и второй группы также было выявлено статистически значимое увеличение показателей жесткости, биологического возраста, снижение эластичности артериальной сосудистой стенки у специалистов ВМФ.

При сравнении всех четырех подгрупп было отмечено, что наименьшая жесткость и наибольшая эластичность артериальной стенки встречалась у курсантов ВМИ с признаками ДСТ ССС, наибольшая жесткость и наименьшая эластичность - у специалистов ВМФ с признаками ДСТ ССС, курсанты и специалисты ВМФ без признаков ДСТ ССС заняли промежуточное положение.

Из этого следует, что на состояние периферических артериальных сосудов, в частности их жесткости и эластичности, влияет множество факторов. С одной стороны, возраст исследуемого человека, при увеличении которого происходит увеличение жесткости и уменьшение эластичности артериальных сосудов, с другой стороны, наличие минимальных признаков ДСТ ССС, которое приводит к уменьшению тонуса у молодых лиц и значимому увеличению у лиц более старшей возрастной категории.

\section{ВЫВОДЫ}

1. Эхокардиографическое исследование является методом качественной оценки наличия признаков ДСТ ССС. Он позволяет диагностировать факт наличия ДСТ ССС, но не степень ее выраженности.

2. Совокупность показателей ЭхоКГ и объемной сфигмографии позволяет диагностировать минимальные признаки ДСТ ССС с вероятностью распознавания от 67,9\% лиц с дисплазией до 87,5\% лиц без дисплазии.

3. Биологический возраст в диапазоне от 20 до 40 лет оказывает большее влияние на периферические артериальные сосуды, чем наличие минимальных признаков ДСТ ССС. ДСТ в разном возрастном диапазоне 
вызывает противоположное действие: у молодых лиц происходит снижение тонуса, повышение эластичности и уменьшение жесткости артериальных сосудов, у более старшего возрастного контингента наблюдаются повышение тонуса, снижение эластичности и увеличение жесткости артериального русла.

\section{СПИСОК ЛИТЕРАТУРЫ}

1. Alekseev A. A. Integrative (systemic, family) connective tissue medicine. Moscow: Lenand; 2005. 517. Russian (Алексеев A. А. Интегративная (системная, семейная) соединительнотканная медицина. М.: Ленанд; 2005. 517).

2. Klemenov A. V. Clinical significance of undifferentiated connective tissue dysplasia. D. Sc. thesis. Moscow; 2005. 238. Russian (Клеменов А. В. Клиническое значение недифференцированной дисплазии соединительной ткани. Дис. ... докт. мед. наук. М.; 2005. 238).

3. Zemtsovskiy E. V. Connective tissue dysplasia of heart. Saint Petersburg: Politeks; 2000. 115. Russian (Земщовский Э. В. Соединительнотканные дисплазии сердца. СПб.: Политекс; 2000. 115).

4. Kadurina T. I., Korzhenevskaya M. A., Mikheev V. S. Genetic analysis of families with generalized connective tissue dysplasia, including the MASSphenotype. Arterial'naya gypertensiya. 1999; 5 (1): 26-7. Russian (Кадурина Т. И., Корженевская M. A., Михеев B. C. Генетический анализ в семьях с генерализованной дисплазией соединительной ткани, включающей MASSфенотип. Артериальная гипертензия. 1999; 5 (1): 26-7).

5. Rabkin E. Activated interstitial myofibroblasts express catabolic enzymes and mediate matrix remodeling in myxomatous heart valves. Circulation. 2001; 104 (21): 2525-32.

6. Milewicz D. M., Urban Z., Boyd C. Genetic disorders of the elastic fiber system. Matrix Biology. 2000; 19 (6): 471-80.

7. Biery N. J., Eldadah Z. A., Moore C. S., Stetten G., Spencer F., Dietz H. $C$. Revised genomic organization of FBN1 and significance for regulated gene expression. Genomics. 1999; 56 (1): 70-7. 
8. Henney A. M., Tsipouras P., Schwartz R. C., Child A. H., Devereux R. B., Leech G. J. Genetic evidence that mutations in the COL1A1, COL1A2, COL3A1, or COL5A2 collagen genes are not responsible for mitral valve prolapse. Br. Heart. J. 1989; 61 (3): 292-9.

9. Nechaeva G. I. The prospects for the implementation of health technologies in the group of patients with dysplasia of connective tissue. Kubanskiy nauchny meditsinskiy vestnik. 2009; 6 (111): 64-4. Russian (Нечаева Г. И. Перспективы реализации здоровьесберегающих технологий в группе пациентов с дисплазиями соединительной ткани. Кубанский научный медицинский вестник. 2009; 6 (111): 64-4).

10. Salomon J., Shah P. M., Heinle R. A. Thoracic skeletal abnormalities in mitral valve prolapse. Am. J. Cardiol. 1975; 36 (1): 32-6.

11. Bon Tempo C. P., Ronan J. A., de Leon A. C., Twigg H. L. Radiographic appearance of the thorax in systolic-click late systolic murmur syndrome. Am. J. Cardiol. 1975; 36 (1): 27-31.

12. Gordon I. B., Rassokhin V. M., Nikitina T. N. Constitutional (genetically determined) vegetative dystonia and connective tissue dysplasia in idiopathic mitral valve prolapse. Cardiologiya. 1984; 1: 63-7. Russian (Гордон И. Б., Рассохин В. М., Никитина Т. Н. Конституционные (генетически обусловленные) вегетативная дистония и соединительнотканная дисплазия при «идиопатическом» пролапсе митрального клапана. Кардиология. 1984; 1: 63-7).

13. Tikhonova O. V., Nechayeva G. I., Druk I. V. Autonomic dysfunction in connective tissue dysplasia in the practice of family doctor. In: Problemy $i$ perspektivy razvitiya semeynoy meditsiny $v$ Sibirskom federal'nom okruge: materialy mezhregion. nauch.-prakt. konf. (Problems and prospects of development of family medicine in the Siberian federal district: materials of the interregional scientificpractical conference). Omsk; 2004: 124-9. Russian (Тихонова О. В., Нечаева Г. И., Друк И. В. Вегетативная дисфункция при дисплазии соединительной ткани в практике семейного врача. В сб.: Проблемы и перспективы развития семейной 
медицины в Сибирском федеральном округе: материалы межрегион. науч.практ. конф. Омск; 2004: 124-9).

14. National recommendations of the Russian scientific society of internal medicine for diagnostics, treatment and rehabilitation of patients with connective tissue dysplasia. Meditsinskiy vestnik Severnogo Kavkaza. 2016; 11 (1): 76. Russian (Национальные рекомендации Российского научного медицинского общества терапевтов по диагностике, лечению и реабилитации пациентов с дисплазиями соединительной ткани. Медицинский вестник Северного Кавказа, 2016; 11 (1): 76).

15. Svistunov A. A., Tsarev O. A., Maslyakova G. N., Mashchenko Yu. V. The clinical course of varicose disease of patients with different severity of connective tissue dysplasia. Saratovskiy nauchno-meditsinskiy zhurnal. 2009; 5 (2): 261-5. Russian (Свистунов А. А., Царев О. А., Маслякова Г. Н., Мащенко Ю. В. Клиническое течение варикозной болезни у больных с различной степенью выраженности дисплазии соединительной ткани. Саратовский научномедицинский журнал. 2009; 5 (2): 261-5).

16. Lysenko L. M., Kuznetsova O. A., Shilina L. V. Pathological changes of cardiovascular system in athletes on the background of a syndrome of physical stress. RMJ. 2015; 4: 239-4. Russian (Льсенко Л. М., Кузнецова О. А., Шилина Л. В. Патологические изменения сердечно-сосудистой системы у спортсменов на фоне синдрома физического перенапряжения. РМЖ. 2015; 4: 239-4).

17. Hereditary disorders of connective tissue. Russian recommendations. Russian society of cardiology. Russian Journal of Cardiology. 2012; 4 (96): 32. Russian (Наследственные нарушения соединительной ткани. Российские рекомендации. Всероссийское научное общество кардиологов. Российский кардиологический журнал. 2012; 4 (96): 32).

\section{ИНФОРМАЦИЯ ОБ АВТОРАХ}




\section{INFORMATION ABOUT AUTHORS}

Ефимов Семен Валерьевич - капитан мед. службы, адъюнкт при кафедре военно-морской терапии, ФГБВОУ ВО «Военно-медицинская академия имени С. М. Кирова» МО РФ, 194044, Россия, г. Санкт-Петербург, ул. Академика Лебедева, д. 6, конт. тел.: +7(999)0291269, e-mail: sve03helper@ rambler.ru

Efimov Semen V. - M. D., Captain of Medical Service, Adjunct of Naval Therapy Department, S. M. Kirov Military Medical Academy the Russian Defense Ministry, 6, Akademika Lebedeva str., Saint Petersburg, Russia, 194044, cont. phone: +7(999)0291269, e-mail: sve03helper@ rambler.ru

Черкашин Дмитрий Викторович - докт. мед. наук, доцент, полковник мед. службы, начальник кафедры военно-морской терапии, ФГБВОУ ВО «Военномедицинская академия имени С. М. Кирова» МО РФ, 194044, Россия, г. СанктПетербург, ул. Академика Лебедева, д. 6

Cherkashin Dmitriy V. - M. D., D. Sc. (Medicine), Assoc. Prof., Colonel of the Medical Service, Heat of Naval Therapy Department, S. M. Kirov Military Medical Academy the Russian Defense Ministry, 6, Akademika Lebedeva str., Saint Petersburg, Russia, 194044

Андрианов Виктор Павлович - докт. мед. наук, профессор, профессор кафедры военно-морской терапии, ФГБВОУ ВО «Военно-медицинская академия имени С. М. Кирова» МО РФ, 194044, Россия, г. Санкт-Петербург, ул. Академика Лебедева, д. 6

Andrianov Viktor P. - M. D., D. Sc. (Medicine), Prof., Prof. of Naval Therapy Department, S. M. Kirov Military Medical Academy the Russian Defense Ministry, 6, Akademika Lebedeva str., Saint Petersburg, Russia, 194044

Аланичев Андрей Евгеньевич - канд. мед. наук, подполковник мед. службы, старший преподаватель кафедры военно-морской терапии, ФГБВОУ ВО «Военно-медицинская академия имени С. М. Кирова» МО РФ, 194044, Россия, г. Санкт-Петербург, ул. Академика Лебедева, д. 6

Alanichev Andrey E. - M. D., Ph. D. (Medicine), Lieutenant Colonel of the Medical Service, Senior Lecturer of Naval Therapy Department, S. M. Kirov Military 
Medical Academy the Russian Defense Ministry, 6, Akademika Lebedeva str., Saint Petersburg, Russia, 194044

Кутелев Геннадий Геннадьевич - канд. мед. наук, капитан мед. службы, преподаватель кафедры госпитальной терапии, ФГБВОУ ВО «Военномедицинская академия имени С. М. Кирова» МО РФ, 194044, Россия, г. СанктПетербург, ул. Академика Лебедева, д. 6

Kutelev Gennadiy G. - M. D., Ph. D. (Medicine), Captain of Medical Service, Lecturer of Hospital Therapy Department, S. M. Kirov Military Medical Academy the Russian Defense Ministry, 6, Akademika Lebedeva str., Saint Petersburg, Russia, 194044

Лидерман Александр Александрович - капитан мед. службы, слушатель ординатуры кафедры госпитальной терапии, ФГБВОУ ВО «Военномедицинская академия имени С. М. Кирова» МО РФ, 194044, Россия, г. СанктПетербург, ул. Академика Лебедева, д. 6

Liderman Alersandr A. - M. D., Captain of Medical Service, Ph. D. student of Hospital Therapy Department, S. M. Kirov Military Medical Academy the Russian Defense Ministry, 6, Akademika Lebedeva str., Saint Petersburg, Russia, 194044 